\title{
Observations on Phase II Price and Wage Controls
}

A NUMBER OF ISSUES CONCERNING the present program of price and wage controls divide members of the Brookings Panel on Economic Activity, as they divide economists generally. This paper does not deal with the more basic of these issues. Rather, it takes as given the decisions to freeze prices and wages last August, and to follow the freeze with a program for Phase II having essentially the objectives of the present one. It considers how well the program is achieving these objectives and whether and how they might be achieved more effectively. The treatment is selective rather than comprehensive. ${ }^{1}$

\section{Early Stages}

Assuming that the administration knew what it was getting into in adopting mandatory wage and price controls, it surely deserves credit at least for courage in electing to use them. And having taken that decision, it did

1. I have discussed some of the more basic issues, and treated some of the more limited ones more fully, in my statements before the Joint Economic Committee of August 31, 1971 (The President's New Economic Program, Hearings before the Joint Economic Committee, 92 Cong. 1 sess., 1971), and of February 25, 1972 (The 1972 Economic Report of the President, Hearings before the Joint Economic Committee, 92 Cong. 2 sess., 1972), Pt. 4, pp. 748-59; in "Phase Two Price Controls," Dun's, Vol. 98 (December 1971), p. 11; and in several speeches that have had limited circulation in mimeographed form. I have adapted portions of the foregoing for use in this paper. 
some things well. First, it gave no indication that it was going to take this course; the public, business, and the unions were taken completely by surprise. The result is in sharp contrast with the terrible mess created in 1950, when discussion of a possible freeze was allowed to go on for nearly six months-and government officials themselves actively contributed to it. Many firms and unions began to "position" themselves for a freeze, causing price increases to accelerate in a way that made the likelihood of a freeze seem all the greater, leading others to begin to position themselvesand others to reposition-until inflation accelerated to the point that the need for a freeze became crystal clear to everyone. And still the freeze was delayed, because a large enough staff had not been assembled. And when it finally came, prices and wages were frozen as of the previous day, instead of several months-or weeks-earlier. Even if only accidentally, as the result of an impetuous decision-making process, no such mess developed this time.

The ninety-day period for the freeze was a good choice: long enough (or it should have been) to prepare what was to follow, yet not so long that the inevitable multitude of anomalies that any freeze creates would become intolerable. However, I believe-and admit that my conviction derives mainly from hindsight - that the wage freeze should have been written to permit during the ninety days automatic interim wage increases of, say, 3 percent-about the average trend of productivity gains-to replace any labor contract that expired during the freeze period, or in lieu of any deferred wage increase of more than this amount that might have come due then under an earlier contract. Admittedly, this provision would have squeezed, for up to ninety days, some businesses whose productivity gains fell short of this average. But it would have been better than giving a windfall gain to every business that experienced any productivity gains, as did the absolute wage freeze. Such a provision might well have drained some of the emotion from the "freezing wages but not profits" plaint, which had at least a smell of justification since productivity surely improved by nearly 1 percent on the average over the ninety-day period. Since I, too, underestimated the emotional impact of this issue, I do not blame the administration for not having tried this simple modification of the wage freeze. But it is something to keep in mind for another time-if there should ever have to be another time.

I am, however, more critical of other early decisions. For example, I believe that it was a thoughtless mistake to have included rents under the 
freeze. Also, the ninety days of the freeze should have been used for intensive administrative preparation for Phase II. I find it almost incredible that offices, furniture, communications, secretaries, administrative personnel, and-worst of all-the rudiments of a professional staff were not ready when the members of the Price Commission and Pay Board were finally appointed and arrived to take up their Phase II duties. As a result, Phase II began under exceedingly heavy and quite unnecessary handicaps. In 1950-51 officials were overconcerned about the need for staff to administer controls; two decades later, they were inexcusably unconcerned.

\section{Coverage of Price Controls}

I shall be brief in discussing the coverage of Phase II mandatory price controls, for my views on this matter have been set forth extensively elsewhere, and were specifically endorsed in the recent report of the Joint Economic Committee; ${ }^{2}$ furthermore, at the beginning of May, the exemption of some five million firms from both wage and price controls accomplished much of what I had urged.

My particular proposal has been that the coverage of Phase II mandatory price controls should be limited essentially to (1) the prices of a list of specified basic materials, and (2) all nonretail prices charged by "big business"-which for practical purposes might well be defined as the roughly 1,500 firms with annual sales in excess of $\$ 100$ million that now must submit proposed price increases to the Price Commission for explicit approval or disapproval. ${ }^{3}$

I thus fully support the exemption from control of all farm product prices. Direct control of these prices requires the most detailed and delicate of regulations, a large and highly expert staff, and an immense administrative and enforcement effort. I do not believe that such controls are necessary or even possible under present conditions. But there are tools that could and should have been used to influence, and generally to stabilize, farm prices. Farm price supports, acreage and marketing controls, and

2. 1972 Joint Economic Report, Report of the Joint Economic Committee on the January 1972 Economic Report of the President, S. Rept. 92-708, 92 Cong. 2 sess. (1972), pp. 23-24.

3. After the May exemptions, controls are estimated to apply to about $1 \frac{1 / 2}{2}$ million firms, including, for example, those making some 50 percent of all retail sales and providing about 60 percent of "selected services." 
import regulations have long been used to support or to raise these prices and the incomes they provide to farmers. That deliberately stabilizing farm prices by these methods would lose more farm votes than it would win consumer votes may be a correct political judgment. But had the political will been available, farm prices need not have been a significant destabilizing influence.

In addition to supporting the exemption of farm product prices, I have advocated abolition of the mandatory control of rents and of retail prices of all consumer goods and services (as well as controls over the prices of a number of the less important industries and of all but the largest firms). This is not because I think that these prices would be stable in the absence of controls, but only that they would rise no more than they will under the kind of controls now being used-or under any controls that might be reasonable under present circumstances.

The Phase II controls in these areas permit sellers to do what they would do anyway. Retailers are simply told to apply their normal markups to the prices of the goods they buy; other sellers are told to pass through all cost increases, with a normal markup. In these essentially competitive industries, this is about all that sellers are ever able to do, except during a period, like wartime, of generalized shortage and excess demand. Although accomplishing nothing, the present controls in these areas require the scarce time and effort of the small price control staff that instead should be devoted to areas where they can make a significant difference. Moreover, these controls lay administrative burdens on those subject to them, and, here and there, quite at random and quite by accident, may impose individual hardships. These burdens and hardships would be defensible only if the controls served some important purpose. Most significant, the public was led to believe that these controls would protect them from rising prices, which they will not-indeed, cannot-do. As people discovered this, they mistakenly concluded that the whole wage-price stabilization effort was a fraud.

The administration knew at the outset that its controls in these areas were essentially meaningless; they were imposed for "psychological reasons." But whatever psychological advantage may derive from an illusion of practically universal controls dissolves into a psychological disadvantage once the public learns the truth-which sooner or later it is bound to do.

It is not impossible to have effective controls over retail and service prices and rents-or over farm product prices, for that matter. We had 
them during World War II, and had to have them, in order to prevent a general and substantial widening of normal retail markups and of the profit margins of landlords and suppliers of services. But, with or without controls, that widening will not occur in today's economy. The only reason for attempting effective control in these areas today would be to compress normal markups and profit margins. But margins in these areas are already so narrow that any tiny compression that conceivably could be achieved would never justify its immense administrative and political costs. Surely, our direct control efforts should be concentrated where they can make a real contribution.

So far as price controls are concerned, this means-to me-basic materials and "big business" (areas that, of course, overlap considerably). The definition of basic materials itself indicates why they should be included among the products subject to price control: They are the materials whose prices are of strategic importance for the costs and prices of other important products. Price controls applicable to big business as such are justified by several considerations:

1. These firms are typically found in markets where competition is least effective in conforming price changes to cost changes.

2. For this reason, and because these firms tend to be highly capitalintensive, big businesses earn profits (plus depreciation) large enough and variable enough to make a real difference for price levels. A reduction or increase of 1 percent in a retailer's price may easily erase or double his profits. This is not the case for most giant industrial firms.

3. Prices charged by the giant industrial firms largely control the prices that their smaller competitors can charge; and their bargaining power largely dictates the prices that their smaller suppliers can charge.

4. In judging whether controls are "equitable," and thus will command the support (or at least tolerance) of labor and public opinion that is crucial for their survival, key attention is inevitably paid to the size and movement of corporate profits, and the giant industrial firms are the source of by far the largest part of these.

5. As a rough rule of thumb, the administrative difficulties and costs of price controls depend more on the number of firms controlled than on the volume of their sales-particularly in the present system, in which the unit of control is basically the firm rather than the product or industry. If manpower is limited - as it is - the effectiveness of controls tends in general to be maximized by concentrating effort on the firms with the largest sales. 


\section{EFFECTIVENESS OF PRICE CONTROLS}

How effective are the present price controls? As I have already indicated, I believe that existing price controls are essentially meaningless for rents and for retail and service prices, and in general for firms with annual sales of less than $\$ 50$ million. Sellers are permitted to do what they would do anyway; even if there should be instances in which the regulations would theoretically hold a price below what the seller otherwise wished to charge, plainly no intention to attempt enforcement exists; even if it did, the regulations would be found to be almost completely unenforceable. We need, then, only to consider the effectiveness of the controls on firms with sales between $\$ 50$ million and $\$ 100$ million (the so-called "reporting firms"), and on those with sales in excess of $\$ 100$ million (the "prenotification firms"). The substance of the regulation is the same for both groups: Firms themselves calculate price ceiling increases for their particular products, which can pass along all cost increases on these products, plus markup, subject to an overriding profits ceiling, about which I will have further comment below. However, the prenotification firms must report their calculations of higher ceilings to the Price Commission, and wait up to thirty days for its approval before putting them into effect. Both groups report their profits quarterly to the commission.

Deliberate violation by a reporting firm could be discovered only by an expensive audit of the firm's records, making compliance mainly voluntary; however, among firms of this size deliberate gross violation is probably infrequent. Changes in the ceiling prices of prenotification firms are a matter of public record, so that deliberate gross violation would be dangerous, and is presumably rare.

The real questions of effectiveness relate, however, not to enforceability, but rather to the character of the ceilings. The Price Commission's basic standard allows a full percentage pass-through of all increases in unit costs (subject to the overriding profits ceiling). Thus, even in principle, it requires no "cost absorption" by business. By business cost absorption, I mean price increases that are smaller than the current increase in per-unit labor and materials costs (after taking account of actual volume and productivity gains). An analogous concept would define "labor cost absorption" as acceptance of average wage and benefit increases that fall short of the sum of the experienced average economy-wide increase in produc- 
tivity plus the experienced increase in living costs. Now it is a matter of simple arithmetic that a wage-price spiral will slow down only if cost absorption (as so defined) occurs on the part of either labor or business or both. This proposition can be easily demonstrated for a simplified economy, but holds approximately true for a more complex one. ${ }^{4}$

4. Assume a simplified economy, in which all output is produced by business, all taxes are direct taxes, and net investment is zero. The following simple algebra summarizes the relationships among changes in wage rates, prices, and profits in such an economy. I assume that wages are revised periodically, but prices more or less continuously. By definition,

$$
P_{t} O_{t} \equiv W_{t} N_{t}+\pi_{t}
$$

where $P$ is the price level, $O$ real output, $W$ the wage rate, $N$ employment, and $\pi$ profits. We assume a known and constant rate of productivity change, $p$.

$$
\frac{O_{t}}{N_{t}}=(1+p) \frac{O_{t-1}}{N_{t-1}}
$$

Suppose, for the moment, no cost absorption is required either by labor or business. We have, then, the standard for wage ceilings:

$$
W_{t}=W_{t-1}(1+p) \frac{P_{t-1}}{P_{t-2}}
$$

Defining the absence of cost absorption by business as the maintenance of a constant percentage of profit to sales (essentially the Price Commission's standard),

$$
\frac{\pi_{t}}{P_{t} O_{t}}=\frac{\pi_{t-1}}{P_{t-1} O_{t-1}}
$$

Since the constancy of the profits share requires as well the constancy of the wage share,

$$
\frac{W_{t} N_{t}}{P_{t} O_{t}}=\frac{W_{t-1} N_{t-1}}{P_{t-1} O_{t-1}}
$$

Substituting from (2) and (3) into (5) and simplifying gives

$$
\frac{P_{t}}{P_{t-1}}=\frac{P_{t-1}}{P_{t-2}}
$$

In other words, if no cost absorption is required (or occurs) either from labor or business, the rate of inflation will be constant. But if equation (4) were replaced by

$$
\frac{\pi_{t}}{P_{t} O_{t}}<\frac{\pi_{t-1}}{P_{t-1} O_{t-1}}
$$

involving cost absorption by business, and/or if equation (3) were replaced by

$$
W_{t}<W_{t-1}(1+p) \frac{P_{t-1}}{P_{t-2}}
$$

it can be shown that

$$
\frac{P_{t}}{P_{t-1}}<\frac{P_{t-1}}{P_{t-2}} ;
$$

that is, inflation will slow down. On the other hand, if negative cost absorption is permitted (ex ante) by either labor or business (or both), the rate of inflation must necessarily increase over time. 
As I have indicated, no cost absorption is occurring in the case of retail prices or services or rents-but, in fact, there is no significant margin for it in these cases. Nor are farmers being asked to accept any limitation on the increase in their net incomes. Quite the contrary. And even in the one area-big business-where cost absorption might effectively have been required in an amount significant enough to make a real difference, the regulation requires none, even in principle. Thus, to whatever extent the control system is slowing down inflation, it must be through requiring some cost absorption by labor.

\section{PRICE INCREASES BASED ON UNIT COSTS}

I shall return shortly to the question whether some significant cost absorption should have been required on the part of big business. But first it is necessary to point out that, quite apart from the question of principle, the technique of ceiling price adjustments calculated by business itself and based on rises in unit costs almost inevitably results in increases in ceiling prices well in excess of those in actual costs-that is, in a widening of permitted profit margins, or negative business cost absorption.

Both the Office of Price Administration (OPA), during World War II, and the Office of Price Stabilization (OPS), during the Korean War, had extensive experience with ceiling price adjustments based on unit cost data submitted by firms. This experience was almost universally evaluated by officials of those agencies as unfortunate. The director of the accounting division of OPA, Herbert F. Taggart, previously and subsequently professor of accounting at the University of Michigan and one of the most distinguished of professional cost accountants, warned his OPA colleagues about the use of unit cost data for setting ceiling prices in these words:

Within broad limits, any producer can conscientiously report to OPA any cost he pleases, and there is frequently no way for OPA to say that the cost submitted is not an accurate reflection of the facts ...5

He explained why this was so in great and convincing detail, and I know of no change in the succeeding thirty years that would invalidate his conclusion.

The Price Commission appears to assume that cost accounting-in-

5. "Costs and Price Control," in U.S. Office of Price Administration, A Manual of Price Control (1943), p. 62. 
cluding the projection of unit cost changes-is a science, not an art. On the contrary, cost estimates and projections involve numerous questions of judgment. Some of these are resolved by the rules of thumb embodied in particular cost accounting systems, but often in ways that are biasedfor example, by the assumption of an unchanged standard volume. Where the rules of thumb do not resolve these questions, human judgment is required, and this judgment inevitably will be exercised in a way favorable to the company's case for a higher price ceiling. Given the great importance of overhead costs, volume is a crucial matter for unit costs; indeed, much of the short-run variation of productivity is also associated with volume changes. Yet it is easy for firms to be pessimistic in estimating sales volume (at least when applying to the Price Commission). During my own years as a price controller, I cannot recall hearing a businessman who was trying to justify a price increase project anything other than a decline from past rates of productivity improvement, and he always had five good reasons. (Of course, very few firms have any experience with measuring productivity - which is, indeed, a conceptual problem of great complexity even in the best of circumstances. $)^{6}$ Moreover, there is vast room for judgment in the measurement of even such apparently simple matters as the unit cost of direct materials: How does a firm treat, for instance, the same material purchased at different prices, discounts and allowances on purchases, the cost of materials transferred from another part of the firm, materials substitutions? If some methods yield larger cost increases, they will inevitably be chosen. Apparently, firms are also allowed to choose the level at which they measure their unit cost changes (before or after the allocation of various departmental, factory, divisional, or company-wide overheads). If so, they will surely choose the level that (with the appropriate markup) produces the largest increase in ceilings.

The closest thing in previous experience to the methods used by the Price Commission was the development by OPS in 1951 of Ceiling Price Regulations 22 and 30, omnibus regulations that required most manufacturers and processors to compute new ceiling prices to reflect increases and

6. Since the above was written, the Price Commission has begun to prescribe rates of productivity increase (by some 400 industry groups) based on historical data. An informal report has it that, prior to this action, the average productivity increase used in filings with the Price Commission was around 1 percent. Even the new procedure, however, fails to take account of the abnormally large productivity gains expected during a period of sharply rising real economic activity, such as that now being experienced. See Price Commission, Office of Public Affairs, "News," Release \#104, May 3, 1972. 
decreases in unit costs. It was an enterprise in which I personally played a major part, over a period of many months. In an attempt to deal with the manifold ambiguities and biases of company cost accounting, the regulations constituted, in effect, detailed cost accounting manuals. Every calculation we made proved that the regulations had to produce more rollbacks of ceilings than increases. Yet plainly they produced mainly increases, often disappointingly large ones. ${ }^{7}$

The similar-and much more loosely prescribed-price control technique has produced what I regard as disappointingly large increases in the present instance. According to a recent release, the Price Commission had, as of May 5, granted approvals of 3,398 filings by prenotification firms for price increases in an aggregate estimated amount of $\$ 8.8$ billion, equal to 3.2 percent of the sales of the products covered by the filings, and to 1.6 percent of the $\$ 551$ billion total sales volume of the companies submitting them. Some 494 applications had been denied and 1,332 were pending. (These data exclude regulated public utilities.) Presumably, most firms eligible for increases have now filed at least once, while others have applied more than once. There are already cases in which a second increase in price ceiling has been approved for the same company and product. Other companies will surely come back for "second helpings," particularly for relief from the higher costs imposed by price increases approved for other firms. In addition, a number of companies have qualified to use the authority that the commission can grant to pass along automatically increases in what are called "volatile" materials costs, and to do so without reporting to it. Others have received upward adjustments of base period prices under various provisions, and other forms of selective relief. Increases due to higher sales taxes, which do not require approval, are also not included in the above figures.

No breakdown by industry has been published, even of the increases specifically approved. However, casual inspection of a number of releases listing increases requested and approved shows that they span a wide range of industries, and that large increases have been approved for a great variety of products. I have been particularly appalled by the substantial increases approved for a number of basic industrial materials.

Increases averaging perhaps 2 percent, or less, for the products of these

7. A detailed review of this experience is contained in Gardner Ackley, "Selected Problems of Price Control Strategy, 1950-1952," a study made for and on deposit with the Office of Defense Mobilization (now the Office of Emergency Preparedness) (August 1953; typewritten), pp. 300-87. 
giant, prenotification firms - and probably somewhat higher (although there is no way of knowing) for the reporting firms-may seem moderate. But since food and service prices, rents, utility and transportation rates, local sales taxes, and other prices will be rising -in most cases substantially -the prospect of meeting the $2 \frac{1}{2}$ percent target for 1972 seems remote if the prices of giant firms rise by 2 percent. One assumes that the giant firms tend to be concentrated in industries with above-average productivity gains, so that their prices ought to rise very little on the average.

Not all of the increases approved have, of course, been put into effect. Press reports speak of the room remaining under existing ceilings for substantial further increases in a number of basic materials prices. In many cases, this room reflects relatively weak markets, not merely generous ceilings. However, the firm-by-firm method of price regulation also clearly makes some ceiling price increases quite academic. If-perhaps for quite accidental reasons-one producer of a relatively standardized product receives approval of a much smaller increase than his competitors can justify, his lower price may often prevent the others from using all of the price increases approved for them.

\section{THE OVERRIDING PROFITS STANDARD}

The weaknesses of the unit cost calculation that I have just described seem already to have permitted a number of firms to run into the limitations imposed by the overriding profits standard. This standard bans price increases that would raise a firm's ratio of profits to sales above the average that prevailed in the best two of the firm's last three fiscal years.

This overriding profits standard appears on its face to be substantially more liberal than the cost-pass-through standard. Assuming that most fiscal years coincide with calendar years, profits were substantially higher as a percentage of sales in both 1968 and 1969, and thus in the average of these years, than in 1971.8 Thus the fact that firms are running into the overriding limitation suggests not the strength of the price control system,

8. Unfortunately, comprehensive corporate profits and sales data for 1971 are still incomplete. However, it appears that the ratio of profits (before tax) to sales in $1971 \mathrm{im}$ proved only moderately from 1970, and fell considerably from 1968 and 1969 . For the combined total of manufacturing, mining, transportation, communication, and electric, gas, and sanitary services, corporate profits before tax as a percent of sales were as follows (based on U.S. Department of Commerce data): 1968-7.3; 1969-6.2; 19704.9. For manufacturing alone (Federal Trade Commission-Securities and Exchange Commission data): $1968-8.8 ; 1969-8.4 ; 1970-6.8 ; 1971$ (author's estimate)-7.5. 
as its supporters now claim, but its considerable weakness. Clearly, the overriding profits standard could permit a considerable widening of business margins since the base period (that is, prior to August 15, 1971)again constituting negative cost absorption.

Suppose, for example, that each of the products of a firm has experienced unit cost increases since the base period (generally the period just prior to August 15, 1971), and each product has thus qualified for a ceiling price increase. If its cost calculations on each product had been based on perfect estimates of volume and productivity, and in all other respects were completely reconcilable with its subsequent over-all financial results, its ratio of profits to sales could never exceed the ratio prevailing during its 1971 base period. Thus, a breach of the overriding standard would be clear evidence of substantially overestimated cost increases, product by product (unless, improbably, it reflected a drastic shift of product mix toward more profitable products).

However, if we relax the assumption that each product has experienced cost and ceiling price increases, the overriding standard might be approached or breached by another route. Suppose, as is true on the average for prenotification firms, cost increases "justified" price increases on only about half of a firm's product line; then overall profits as a percentage of sales could easily exceed the 1971 base period rate if all cost increases on this half of the line were no more than offset by ceiling price increases while unit costs declined on the other half-as a result of volume or productivity changes or other factors-and prices did not decrease equivalently. Indeed, even receiving no ceiling price increases, a firm could easily find its profits above the overriding standard-if its unit costs on many or most of its products had declined more than its prices.

The ambiguity that therefore must attach to a breach of the overriding profits standard adds to the problems of both practice and principle that the application of this standard raises:

1. The strong element of randomness and seasonality in the quarterly profits of many companies force the test of whether they exceed the standard to await the completion of a full fiscal year's operation following the approval of price increases. For many firms, this means early 1973, or even later. (For other firms, whose fiscal years end on, say, March 31, the test of compliance comes much earlier.)

2. What penalties should be imposed for violations of the profits standard? Criminal and civil penalties seem to be justified only if bad faith 
were proved in the firm's estimates of cost increases; and I should think this an exceedingly difficult case to sustain. Therefore, the only appropriate "penalty" would seem to be the requirement that prices be reduced, and, possibly, refunds made. Unfortunately, most price reductions and refunds cannot reach consumers, and would therefore only redistribute profits from one set of firms to another. I doubt that refunds to the Treasury could be required, as was at one time discussed.

3. The Price Commission has concluded, at least for the present, that a firm whose profits exceed the overriding standard is in violation only up to a maximum amount equivalent to the dollar value of its approved price increases, or the dollar value of the excess profit margin, whichever is less. Although the commission apparently discussed a "whichever is greater" rule, I cannot believe that a legal proceeding under the present law and regulation could possibly support it.

4. Where firms' overall earnings begin to exceed the profits standard, should price ceiling rollbacks below the price levels of August 1971 now be required as a matter of policy even though no question of violation is involved? In my judgment, efforts to obtain rollbacks ought to be far more selective than is implied by such a standard; I am not even sure that any significant mandatory rollback effort is appropriate in a short-term, emergency program. (Some might be pursued on a "voluntary" basis, however.)

\section{PRICE-WAGE CONTROLS AND INCOME SHARES}

The question of possible rollbacks of prices below August 1971 levels when profits exceed some earlier ratio to sales raises the broader question of the appropriate form for a profits standard during a period when profits can be expected to rise sharply for purely cyclical reasons-as is the case now and for the year ahead.

We know that aggregate corporate profits in recent years (especially after 1968) are among the lowest of the entire postwar period, whether expressed as a percentage of corporate national income or as a rate of return on sales or assets, and even when adjustments are made for changes in depreciation methods. ${ }^{9}$ Clearly, controls should not be expected to freeze the income shares of wages and profits at their 1971 ratios. Unfor-

9. See, for example, Survey of Current Business, Vol. 52 (March 1972), Table 5, pp. 26-27. 
tunately, however, we do not know whether the low profits share of 1971 reflects a narrowing of price-cost relationships, or merely the recent low rates of capacity utilization and disequilibrium in the relation of variable to overhead costs. We do not know, that is, whether the pricing formulas used on the average by big business-usually some variant of markup over some portion of standardized unit costs-actually shifted between, say, 1966 and 1971, and, if they did, whether the shift was toward wider or narrower margins over the cost elements included. With the restoration of reasonably full-capacity operations, would a continuation of the price-cost relationships that produced the 1971 price level generate lower or higher aggregate profits (as a percent of sales, equity, or corporate national income) than were realized, for example, in 1966? Questions like these are of vital importance for the design of price control standards (or for other systems of incomes policy); yet we know far too little about the empirical relationships involved.

The answers to such questions would be helpful in resolving the problem raised earlier with reference to past and current policy: Should business (or at least big business) be expected to contribute to the slowing down of inflation, through a requirement that it absorb some part of unit cost increases? Or should cost absorption be required only on the part of labor? My own view is that some cost absorption should indeed be required on the part of big business-surely in principle, and, if possible, in practice. Not to have required it implies an answer to the question of fact about price-cost relationships that we do not now have. Imposing such a requirement now would not demand a decision for all time on proper income shares; nor would it prevent a very substantial rise in the actual profits share during the period immediately ahead. To the extent that such a requirement could be made effective, it could substantially speed the reduction in the rate of inflation.

\section{RECOMMENDATIONS REGARDING PRICE CONTROLS}

On the basis of the above discussion, I recommend the following immediate changes in the substance of the current price controls:

1. The Price Commission should revise its basic regulation for big business so that an explicit element of cost absorption is required, at least in principle.

2. It should revise its procedures to provide a far more careful and skeptical review of filings for price increases from large firms, demanding 
justification and documentation for every cost figure. The more important the dollar volume involved and the more strategic the commodity, the closer its review should be, even including sending its own accountants to inspect records of firms. On the basis of such a review, many more requests for price increases would be rejected or cut back. As an old price controller, I cannot believe that even a cursory review would fail to turn up far more cases of obvious overestimates of cost increases, use of pessimistic assumptions regarding productivity or sales volume, conceptually inappropriate measurements of cost factors, and, indeed, complete misunderstanding of the regulations.

3. Instead of regarding its job as merely the mechanical application of its standards, regardless of where this may lead, the commission should be exercising active judgment, persuasion, and perhaps a little arm-twisting in an effort to delay or minimize the increases it approves, especially for strategic materials that affect the basic level of costs for other industries, or for major consumer items. For example, it might well have tried to avoid an increase in automobile prices last fall, an increase that may prove to have been inappropriate even under the commission's own standards.

4. There surely are many appropriate cases in which the commission should specify product-wide or industry-wide adjustments of base period prices, calculated according to its own studies and projections of costs, productivity, sales volume, and profits. In this way, it can assure tighter application of its (revised) standards than is possible in a firm-by-firm procedure.

5. The commission should abolish its so-called term-limit-pricing system, under which a firm may qualify for an average ceiling price increase, over a year, of up to 1.8 percent (formerly 2 percent) of its sales volume, to be spread as it pleases; and it should revoke all previous increases granted under this provision.

6. Where it is breached, the overriding profits standard should be applied as vigorously as possible to require widely publicized rollbacks of ceiling price increases (but not of base prices).

\section{Wage Controls}

My treatment of wage controls is brief, in part because I have taken so much space for price controls, in part because wage controls are economically simpler-if politically more complex, and in part because I know much less about them. 
I have recently encountered for the first time the Pay Board's Statistical Releases. Their data challenge severely my preconceptions about the average pay and benefit increase that the board has permitted. The latest release, dated May 12, reports a cumulative average of wage and benefit increases approved through May 5 of only 4.3 percent, in some 951 cases involving 1,000 or more employees. (The board's calculations all relate to the year beginning November 14,1971 .) This average reflects both the provisions of new contracts and approved increases under preexisting contracts. ${ }^{10}$

To be sure, these data do not include construction contracts under the jurisdiction of the Construction Industry Stabilization Committee, where approvals have run substantially higher. Still, fears that I have expressed earlier that the average wage increase this year would be in the range of $61 / 2$ to 7 percent may prove exaggerated. If we accept the Pay Board data, we could justify instead an estimate of only 5 or $5 \frac{1}{2}$ percent for the year.

To be sure, these data from the board are not entirely consistent with the latest data from the Bureau of Labor Statistics (BLS), which show that, in the first quarter of 1972, the annual rate of increase of manhour compensation in the private nonfarm economy was 9.2 percent, which considerably exceeds any recent quarter. But in part this reflects a post-freeze bulge; when the first-quarter increase is averaged with the two preceding quarters, the rate of increase drops to less than $6 \frac{1 / 4}{4}$ percent. In the two quarters prior to the freeze, the increase averaged more than a full percentage point higher. Average hourly earnings in the private nonfarm economy, adjusted for overtime in manufacturing and for interindustry shifts, increased at an annual rate of 8.5 percent in the first quarter of 1972 . When the two preceding quarters are averaged in, the increase is about $61 / 4$ percent, down more than a full percentage point from the first half of 1971 . Thus these data, too, support a conclusion that wage increases have been slowed down during the period of controls, but are not consistent with an estimate of a 5 to $5 \frac{1}{2}$ percent wage and benefit increase in 1972.

10. The average appears not to include zero increases-relating, for example, to employee groups that have not yet completed negotiation, or whose workers have zero increases due this year under existing contracts. However, there appear to be some very small numbers included, where only certain features (perhaps of deferred increases) have required approval by the board. Increases for employee groups of less than 1,000 are not required to be approved or reported to the board so long as they do not exceed 51/2 percent. Larger increases for a few such groups have been approved, but cover a trivial number of workers. 
The Pay Board data seem even less consistent with the BLS series on the average wage and benefit decisions in "major collective bargaining situations." Presumably, these averages should be directly comparable with the Pay Board data. Although the BLS estimates for first quarter settlements show substantial declines from previous quarters, they remain, in an absolute sense, substantially above the Pay Board averages. For example, the average first-year adjustment contained in these settlements is reported as 9.3 percent for wages and benefits, and 8.4 percent for wages alone. The respective averages for the full year 1971 were around 13.1 percent and 11.7 percent, respectively. Thus the data indicate a substantial decline in the average size of settlements. (The decline is less when measured over the life of the contracts: for wages and benefits, from 8.7 percent in all of 1971 to 8.1 percent in the first quarter of 1972.) Reconciliation of these data with the Pay Board figures is possible only by assuming a wide gap between the settlements in "major collective bargaining situations" and those obtained by smaller unions and unorganized workers.

\section{THE PROSPECTS}

Suppose we assume that wage rate increases over the balance of 1972 average no more than 6 percent. Over the past twelve months (thus including the period of the freeze)-and over the four months since the freeze ended - the annual rate of consumer price increases averaged nearly $3 \frac{1}{2}$ percent, which also reflected a substantial slowing down. Although quarterly changes in productivity in the nonfarm economy fluctuate somewhat erratically, they have averaged nearly $3 \frac{1}{2}$ percent over the pașt four quarters, a rate that might be expected to be exceeded over the next several quarters. Thus, labor would be currently absorbing cost increases (on my definition) to the extent of about 1 percent. Yet this absorption seems unlikely further to reduce the rate of inflation during the balance of 1972 if, as appears now to be the case, price controls should continue to allow a widening of business markups and farm policy some further rise in farm incomes. My guess thus is that the rate of increase of consumer prices will remain in the 3 to 4 percent range. On the other hand, if business were effectively prevented from widening its markups and farm prices were reasonably stabilized, the administration's target might well be attained. But I confess that I do not expect this to happen. The above num- 
bers are, I hardly need add, illustrative orders of magnitude, rather than precise forecasts.

It is my impression that the U.S. public will not be satisfied with continuing inflation in the 3 to 4 percent range. If a further slowing down were to be required in 1973, the chances of obtaining labor's acquiescence in a reduction of the rate of wage increases to the neighborhood of 5 percent for 1973 would seem greatly improved if provision were made for some effective cost absorption by big business, and if it were possible to create some reasonable confidence that a lower rate of consumer price increase would prevail in the period ahead. The tightening in price controls that $I$ have suggested would not necessarily assure this-particularly if farm prices should spurt again. But it could make an important contribution to a political and expectational environment favorable to a further slowing down of inflation. 